\title{
Nurse Knowledge, Attitude and Implementation of Safe Patient Transportation in Preventing the Spread of Covid-19
}

\section{Yulia Wardani ${ }^{1,{ }^{*}}$, Sumarti Endah Purnamaningsih Maria Margaretha ${ }^{2}$, and Wiwi Kustio Prilliana ${ }^{2}$}

${ }^{1}$ STIKes Panti Rapih, Yogyakarta

${ }^{2}$ Politeknik Karya Husada, Yogyakarta

\section{ORCID}

Yulia Wardani: https://orcid.org/0000-0001-5334-5721

Corresponding Author: Yulia Wardani; email: yulia_wardani@ stikespantirapih.ac.id

Published: 7 February 2022

Publishing services provided by Knowledge E

(c) Yulia Wardani et al. This article is distributed under the terms of the Creative Commons Attribution License, which permits unrestricted use and redistribution provided that the original author and source are credited.

Selection and Peer-review under the responsibility of the IVCN Conference Committee.

\section{G OPEN ACCESS}

Abstract. One of the ways to prevent the spread of Covid-19 is by planning and implementing appropriate transportation for Covid-19 patients which is efficient, effective and safe. There are many factors that influence the implementation of transportation for Covid-19 patients including the characteristics of nurses, hospital protocols, and special routes of transportation. The aim of this study was to analyze the correlation between nurses' knowledge and attitudes, and the implementation of Covid19 transportation. A cross-sectional approach was used with a descriptive-correlative design. A sample of 211 nurses was attained using the snowball sampling technique. Data analysis involved frequency distribution, the Chi-square test and multivariate logistic regression. A significant correlation was found between the knowledge level of the nurses and the implementation of transportation for Covid-19 patients $(p<0.001)$ and between the attitudes of nurses and the implementation of Covid-19 transportation $(p<0.001)$

Keywords: attitude, Covid-19, implementation, knowledge, patient transportation

\section{Introduction}

The high level of infectivity of Covid -19 has lead to a rapid increasement to create many new cases and outbreak in several waves. The COVID-19 epidemic control is moving from public health control strategic to mitigation strategic in some locations [1] The main control strategy is contact tracing. Its effectiveness depends on the presymptomatic and asymptomatic disease pattern. With $100 \%$ of symptomatic cases, an RO of 1.5 can be controlled with $50 \%$ of the contact cord. With an RO of 3.5, it takes $90 \%$ [2] During this initial phase, three important and critical tasks in providing time-critical information for crisis mitigation are: (1) establishing central epidemiological parameters, such as baseline reproductive numbers, which can be used for short-term prediction, (2) simulating the effects of various possible interventions which aimed to mitigate the outbreak and (3) estimating the actual effects of the outbreak. Actions are taken not 
only to make quick adjustments but also to have a short-term prediction of the outbreak period [3]

The global spread of COVID-19 alerts many hospitals to tackle this disease. One important issue was the transportation of infected COVID-19 patient that can be counted as one of the mode of transmission of the disease. This transportation of Covid19 patients will lead to break many cases which causes tonosocomial spread and will delay the efforts to break the chain of transmission of Covid-19 spread off [4] The new shifting transportation challenges associated with COVID-19 have important implications for accessing the healthcare system. The health care system and health care insurance companies have responded to COVID-19 by delaying non-emergency medical procedures. However, for people who still need immediate health care, the effects of COVID-19 on transportation can cause significant problems in care, especially for people with certain health conditions with certain health care treaments [5]

The data about nursing care, especially in Covid-19 patients transportation for the covid-19 patients are very limited and this transportation issue might lead the health status of an area is becoming worse. This study aimed to describe on how some essensial factors such as demography profile, knowledge and attitudes of the nurses correlate with the implementation of transportation system of of COVID-19 patients in some health care services.

\section{Research Methods}

This quantitative research used a descriptive-correlative analytic design. The first description was to show the demographic profile of the participants, the available of transportation protocol for Covid-19 patients, knowledge level, attitude of the nurses on transportation procedure. This descriptive process was then followed by the correlative analysis process between demography profile, transportation protocols and the implementation of transportation system in handling Covid-19 patients. Using cross sectional approachment, that some variables on this research were measured or collected simultaneously and at the same time [6] The independent variables in this study were demography profile, knowledge anda attitude of the nurses and Covid-19 transportation protocol. On the other hand, the dependent variable was the implementation of Covid-19 patients.

With snowball sampling technique, 211 nurses as participants of this study were gathered. Snowball sampling technique is a technique of attaining the participants that started from the first participant first, then this first participant will show/ refer 
the researcher to the second participant that fill the criteria to become the second participant, third participant and so on until the researcher able to provide complete data by looking for other people who can be used as data sources [7]

The data were collected by filling out online questionnaires delivered by the researcher. The data used primary data that obtained online via google form by distributing some instrument about Knowledge, Attitude and Implementation Questionnaires. Those instruments were compiled by the researchers and had been tested with the validity value of all questionnaires $>0.349$ and reliability for knowledge $>$ 0.826 , attitude $>.062$ and implementation $>0.841$. Data collection was started on April 15 to May 10, 2020. Every participants were asked to fill the document of agreement stating that they were willing to participate in this research at time frame. This study implemented the ethical principle of human research namely confidentiality, justice, and beneficence.

To describe the data in a frequency distribution, the data were then analyzed using the SPSS 21 with a descriptive analysis. This study used univariate data analysis using frequency distribution tables to study demographics and descriptions of knowledge, attitude and implementation of Covid-19 patient transportation. The bivariate analysis test used the Chi Square test to explore the relationship between demographic profile of the participants, knowledge and attitude in the implementation of Covid-19 patient transportation process. Multivariate analysis using logistic regression test with the enter method to find out the most dominant predictor variables related to the implementation of Covid-19 patient transportation

\section{Result}

The characteristics of the demographic profile of the participants are presented as follows.

The results of the univariate analysis in table 1 indicated that the characteristics of the participants were dominated by female 122 (57.8\%), aged between 21-40 years old were 145 (68.7\%), 129 (61.1\%) participants had Bachelor degree as their education background and 134 (63.5\%) participants working in covid-19 ward /referral Covid unit.

The availability of transportation protocol for Covid-19 patients along with special routes for Covid-19 patients can be seen in graphs 1 and 2 as follows: 
TABLE 1: The Demografi Profile of the Participants $(n=211)$

\begin{tabular}{l|l|l}
\hline Variable & Frequency (N) & Persentage (\%) \\
\hline Gender & 122 & 57,8 \\
\hline Female & 89 & 42,2 \\
\hline Male & 211 & 100 \\
\hline Total & & \\
\hline Age & 145 & 68.7 \\
\hline $21-40$ & 66 & 31.3 \\
\hline 40 & 211 & 100 \\
\hline Total & & \\
\hline educational & & \\
\hline background & 82 & 38.9 \\
\hline Diploma & 129 & 61.1 \\
\hline Bachelor & 211 & 100 \\
\hline Total & & \\
\hline Work Unit & 77 & 36.5 \\
\hline Non Covid-19 Ward & 134 & 63.5 \\
\hline Covid-19 Ward & 211 & 100 \\
\hline Total & &
\end{tabular}

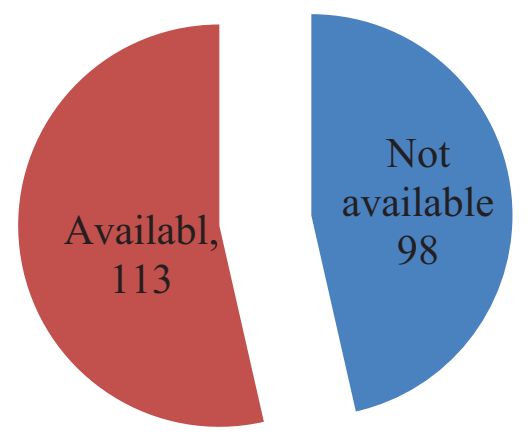

Figure 1: Availability of Covid-19 patient transportation protocols.

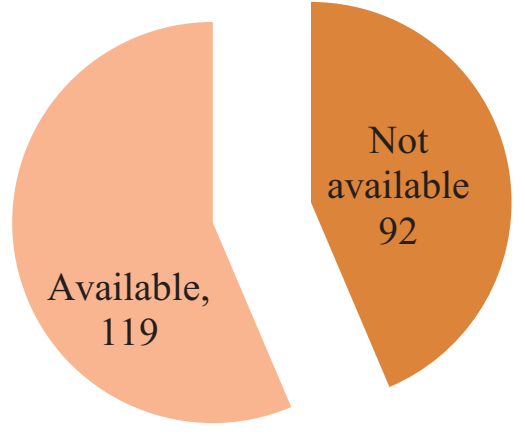

Figure 2: Availability of special lanes for Covid-19 patients.

Participants who indicated that they had a Covid-19 patient transportation protocol at their workplace were 113 people (53.6\%) and participants who stated that they had a special route for Covid-19 patients were 119 people (56.4\%). 
TABLE 2: The distribution of the Knowledge level, Attitude and Implementation of Covid-19 Transportation $(n=211)$

\begin{tabular}{l|l|l} 
Variable & Frequence & Percentage (\%) \\
\hline Knowledge & & 11,4 \\
\hline Low & 24 & 31,8 \\
\hline Moderate & 67 & 56,9 \\
\hline High & 120 & 100 \\
\hline Total & $\mathbf{2 1 1}$ & \\
\hline Attitude & & 46 \\
\hline Negatif & 97 & 54 \\
\hline Positif & 114 & 100 \\
\hline Total & $\mathbf{2 1 1}$ & 60,2 \\
\hline Good & 127 & 39,8 \\
\hline Poor & 84 & 100 \\
\hline Total & $\mathbf{2 1 1}$ &
\end{tabular}

The results showed that most of the participants' knowledge about the transportation of Covid-19 patients was high with 120 participants (56.9\%), majority had a positive attitude as many as 97 participants (46\%) and as many as 127 participants (60.2\%) had good implementation of covid-19 transportation

Table 3 showed that participants who carried out the transportation procedure in a good level were mostly female participants as 83 (39.3\%), age range $21-40$ years as many as 110 people (52.1\%), with bachelor degree of education background as 87 participants (41.2\%), working at the Covid-19 referral hospitals as 98 participants (46.4\%), having a transportation protocol of 79 participants (37.4\%) and having a special route for Covid-19 patients as many as 83 participants (39.3\%). The results of the statistical test showed that there was a relationship between gender $(p=0.006)$, age $(p=0.000)$, education $(p=0.007)$, place of work $(p=0.000)$, health protocol $(p=0.002)$ and the special route for COVID-19. $19(p=0.001)$ with the implementation of transportation for covid-19 patients.

The implementation of good Covid-19 patient transportation was mostly in the high knowledge category with 89 participants (42.2\%) and the majority attitude was in the positive category as many as 97 participants (46\%). The results of the statistical test show that there is a significant correlation between knowledge and the implementation of transportation for COVID-19 patients with $p$ value of $0.000(p<0.05)$ and a correlation between attitude and the implementation of transportation of Covid-19 patients with value of $p=0.000(p<0.05)$. 
TABLE 3: The Correlation between Demography Profiles and the Implementation of Covid-19 patient transportation $(n=211)$

\begin{tabular}{|c|c|c|c|c|}
\hline \multirow[t]{2}{*}{ Demography profile } & \multicolumn{2}{|c|}{$\begin{array}{l}\text { Implementation of Covid-19 } \\
\text { patients transportation }\end{array}$} & \multirow{2}{*}{$\begin{array}{l}\text { Total } \\
\text { N (\%) }\end{array}$} & \multirow[t]{2}{*}{ P-value } \\
\hline & Baik & Buruk & & \\
\hline & $\mathrm{N}(\%)$ & $\mathrm{N}(\%)$ & & \\
\hline Gender & & & & 0,006 \\
\hline Female & $83(39,3)$ & $39(18,5)$ & $122(57,8)$ & \\
\hline Male & $44(20,9)$ & $45(21,3)$ & $89(42,2)$ & \\
\hline Total & $127(60,2)$ & $84(39,8)$ & $211(100)$ & \\
\hline \multicolumn{5}{|l|}{ Age } \\
\hline $21-40$ & $110(52,1)$ & $35(16,6)$ & $145(68,7)$ & 0,000 \\
\hline$>40$ & $17(8,1)$ & $49(23,2)$ & $66(31,3)$ & \\
\hline Total & $127(60,2)$ & $84(39,8)$ & 211(100) & \\
\hline Educational background & & & & 0,007 \\
\hline Diploma & $40(19)$ & $42(19,9)$ & $82(38,9)$ & \\
\hline Bachelor & $87(41,2)$ & $42(19,9)$ & $129(61,1)$ & \\
\hline Total & $127(60,2)$ & $84(39,8)$ & $211(100)$ & \\
\hline Work unit & & & & 0,000 \\
\hline Non Covid-19 ward/referral & $29(13,7)$ & $48(22,7)$ & $77(36,5)$ & \\
\hline Covid-19 ward/referral & $98(46,4)$ & $36(17,1)$ & $134(63,5)$ & \\
\hline Total & $127(60,2)$ & $84(39,8)$ & $211(100)$ & \\
\hline Transportation protocol & & & & 0,002 \\
\hline Not available & $48(22,7)$ & $50(23,7)$ & $98(46,4)$ & \\
\hline Available & $79(37,4)$ & $34(16,1)$ & $113(53,6)$ & \\
\hline Total & $127(60,2)$ & $84(39,8)$ & $211(100)$ & \\
\hline \multicolumn{4}{|c|}{ Special route for Covid-19 patient } & 0,001 \\
\hline Not available & $44(20,9)$ & $48(22,7)$ & $92(43,6)$ & \\
\hline Available & $83(39,3)$ & $36(17,1)$ & $119(56,4)$ & \\
\hline Total & $127(60,2)$ & $84(39,8)$ & 211(100) & \\
\hline
\end{tabular}

Based on the results of the analysis test, the candidate variables for which the logistic regression test was carried out were variables with the results of the chi square statistical test $p<0.05$. Because all variables have a value of $<0.05$, all variables meet the requirements for regression testing. The results of the logistic regression test are presented in table 5 below

The results of the logistic regression statistical test according to table 5 showed that age and attitude had $p$-value of 0.000 each and was the lowest $p$-value. Therefore, age and attitude were the dominant factors related to the implementation of the transportation of COVID-19 patients 
TABLE 4: The Correlation between Knowledge and Attitude of Participants with The Implementation of Transportation for Covid-19 Patients ( $n=211)$

\begin{tabular}{|c|c|c|c|c|}
\hline \multirow[t]{2}{*}{ Variable } & \multicolumn{2}{|c|}{$\begin{array}{l}\text { Implementation of Covid-19 } \\
\text { patients trasnportation }\end{array}$} & \multirow{2}{*}{$\begin{array}{l}\text { Total } \\
\text { N (\%) }\end{array}$} & \multirow[t]{2}{*}{ P-value } \\
\hline & Good & Poor & & \\
\hline & N (\%) & N (\%) & & \\
\hline Knowledge & & & & 0,000 \\
\hline Low & $2(0,9)$ & $22(10,4)$ & $24(11,4)$ & \\
\hline Moderate & $36(17,1)$ & $31(14,7)$ & $67(31,8)$ & \\
\hline High & $89(42,2)$ & $31(14,7)$ & $120(56,9)$ & \\
\hline Total & $127(60,2)$ & $84(39,8)$ & $211(100)$ & \\
\hline \multicolumn{5}{|l|}{ Attitude } \\
\hline Negatif & $30(14,2)$ & $67(31,8)$ & $97(46)$ & 0,000 \\
\hline Positif & $97(46)$ & $17(8,1)$ & $114(54)$ & \\
\hline Total & $127(60,2)$ & $84(39,8)$ & $211(100)$ & \\
\hline
\end{tabular}

TABLE 5: Results of Multivariate Logistics Regression Analysis Demography Profiles, Attitude and Knowledge related to the Implementation of Covid-19 Patient Transportation $(n=211)$

\begin{tabular}{l|l|l|l|} 
Variable & OR & Cl 95\% & P-value \\
Demography & & & \\
\hline Age & 9,059 & $4,635-17,705$ & 0,000 \\
\hline Gender & 2,177 & $1,239-3,824$ & 0,004 \\
\hline Educational background & 0,460 & $0,260-0,812$ & 0,001 \\
\hline Work unit & 0,222 & $0,122-0,404$ & 0,001 \\
\hline Transportation protocol & 0,413 & $0,235-0,726$ & 0,163 \\
\hline Covid-19 special route & 0,398 & $0,226-0,700$ & 0,769 \\
\hline Knowledge & 0,059 & $0,038-0,126$ & 0,001 \\
\hline Attitude & 0,078 & $0,040-0,154$ & 0,000 \\
\hline
\end{tabular}

\section{Discussion}

The study was conducted in the early - middle stages of the COVID-19 outbreak in non-epidemic areas where are some areas still as critical areas. An analysis of the knowledge level of health workers and the factors that influence their attitude and practices regarding transportation for patients can provide some information for preventing further spread of the epidemic among health workers. Female participants were nurses. The data confirmed that nursing in a feminist profesion that the gender of female dominates this profession around the world. Caring behaviour, nurturing and cultivating the emotion, feeling and hope behind the procedures and nursing treatments happened very well in the hand of female. The average age of the nurses in this study were 23-47 years. The data indicated that all the participants' age range in the productive age. These data were really correlated with the level of the education of the 
participants that hold a bachelor's degree and had work experienced of more than nine years. In this condition nurses had enough knowledge and experiences on how served the Covid-19 patients that very infectious by conduction patients and nurses in handling infectious management or infectious control management including the transportation procedure of the Covid-19 patients safely. Frontline health workers including nurses who work about 8 hours per day should know and able to perform the transport protocols for patients with Covid-19 [8]

The results of [9] research showed that nurses' knowledge and attitude in transporting patients to COVID-19 referral hospitals were good enough. Therefore, unnecessary referrals to hospitals that have recently experienced the current pandemic with extra burden to the health care workers can lead to burnout of hospital staffs, decrease the quality of health services and increase the career rate of COVID-19 [10] Knowledge and attitude of nurses regarding these condition including the prevention strategies or techniques in referring and transporting the patients to the hospital were found to be increasing much higher. Although most of the nurses are implementing the recommendation for personal protective devices in transporting COVID-19 patients but the fact the Covid-19 infection spread off are still high and being concerned.

To emphasize the result of this study, the knowledge and attitude of nurses in transporting COVID-19 patients in China were shown to be very satisfactory. Various measurement including intensive training for the health care workers, strengthened personal protection, environmental disinfection and environment safety are important measurements after exposuring to the Covid-19 patients and it becomes the concern of the hospital management. Those issues in the workplace are contributor factors to ensure the safety of health care workers at the hospital's East - West Lake Fangcang shelter [11] Health care workers who assigned as the medical assistance team experienced lower levels of fatigue and had excellent knowledge and attitudes in transporting COVID-19 patients. Another issue that faced by health care workers is a compassionate fatigue and complacency in health care workers. This issue should be emphasized and require targeted significant interventions [12]

Fu et aa [13] identified that treatment for patients with lung cancer has been affected by the epidemic to some extent. Nurses provided very high health services related to knowledge and attitude in carrying out transportation of the COVID-19 patients and obeying the hospital protocol for Covid-19 patient transportation. The demand for medical support among patients with lung cancer or other life-threatening diseases should receive sufficient attention, especially when carrying out transportation during the current COVID-19 outbreak. 
After the decription of the demography profile was analyzed, the data on the correlation between demography profilr of the paraticipants and the implementation of transportation for Covid-19 patients was analyzed. Table 3 showed that the results of the statistical test and indicated that there was a significant correlation between gender $(p=0.006)$, age $(p=0.000)$, education $(p=0.007)$, place of work $(p=0.000)$, health protocol $(p=0.002)$ and the special route for COVID-19. $19(p=0.001)$ with the implementation of transportation for covid-19 patients. It means all the demography factors have strong relationship with the implementation picture of transportation of Covid-19 patients. The results identified that the higher of educational background, the older of the nurses, the longer of work experiences and the better of health protocol and route for transportation are the better is the implementation of Covid-19 transportation level.

According to [14] through the implementation of epidemic prevention and control strategies, the work of female anesthesia nurses carried out the transportation of Covid19 patients orderly and safety in nursing department. This epidemic prevention and control strategy is based on China's national conditions, local epidemic situation, and hospital conditions, so that anesthesi nurse colleagues can choose their strategies based on their own specific conditions. Khosravani and Phavalan (2020), introduced the concept of a protected stroke code during a pandemic period, as in the case of COVID-19, and provide a framework for nurses to consider key considerations including screening, personal protective equipment, and transpostation devices for patients, with female characteristics and at the age of 25-49 years. These considerations and suggested algorithms can be used and adapted for local practice.

Utilizing transportation services for nurses can help increase nurses' access to actions. In this study, the characteristics of the participants were mostly female with the last education being a bachelor's degree in nursing and the average age was 23-47 years. This transportation can helped transport patients and reduce delays in medical care [15] The COVID-19 pandemic has reduced by a quarter number of stroke and thrombectomy patients performed at the Comprehensive Stroke Center, but has not affected by the quality of metric care of the health care workers. During the lockdown period, there was an overload of emergency calls but fewer Stroke Code activations, especially in elderly patients. Hospital contingency plans, in transporting patients and warnings targeted at the population must act together to gain a better protection for the stroke care chain during a pandemic [16]

The relationship between knowledge and attitude with the implementation of transportation for Covid-19 patients. The results of the statistical test on table 4 showed that there is a significant correlation between knowledge and the implementation of 
transportation for COVID-19 patients with $p$ value of $0.000(p<0.05)$ and a relationship between attitude and the implementation of transportation of Covid-19 patients with value of $p=0.000(p<0.05)$. The level of knowledge and attitude of nurses in transporting patients is in accordance with protocols related to COVID-19, risk awareness, in various COVID-19 prevention and testing behaviors [17] Health care workers play a very important role in fighting the pandemic. Therefore, their knowledge on the patient transportation and their willingness to work are needed to prevent disease transmission and reduce morbidity and mortality. Adequate training can be a means to overcome these shortcomings [18]

Nurses will be the pioneers in dealing with Covid-19 cases that arise around the world. Knowledge and attitude performance of nurses and also their concerns for patient safety need to be recognized in carrying out patient transportation and it will be improved significantly. These needs should be translated into effective policies. This may involve extreme and unnecessary measurement [19] COVID-19 prevention practices are not satisfactory enough among educated people in Ethiopia. Women, those who are elderly, those who believe in reinfection by COVID-19, those who are suffering from Covid-19. Good knowledge and attitude about symptoms, prevention methods, and knowledge of self-protection have better prevention practices in carrying out patient transportation [20]

The results of the logistic regression statistical test according to table 5 indicated that age and attitude have $p$-value of 0.000 each and is the lowest $p$-value. Therefore, age and attitude are the dominant factors related to the implementation of the transportation of COVID-19 patients.

In conclusion, most nurses showed positive attitudes and low-risk practices related to COVID-19 in transporting COVID-19 patients [21] With regarding to nurses, concern for professional and patient safety is identified, as they adopt good behavior for pandemic prevention and control through the used of covid-19 patient transportation. The subjective aspects of the professionals involved must be considered, such as technical and psychological preparation, which are fundamental aspects both for serving the community and for safety when transporting patients and professionals in terms of virus exposure [22]

\section{Conclusion}

This study concludes that there is a significant colleration between demography profile and the implementation of Covid-19 patient transportation, then there was a relationship 
between attitudes and knowledge with the implementation of Covid-19 transportation. Age and Attitude are the dominant factors related to the implementation of the transportation of Covid-19 patients. The results of this study recommend for the hospital management to optimize the implementation of Covid-19 patient transportation by evaluating the implementation of transportation routinely according to existing protocols and conducting some training for nurses in the implementation of Covid-19 patient transportation to increase the effectiveness in handling the transportation for the patients with Covid-19.

\section{References}

[1] Rocklöv J, Sjödin H. High population densities catalyse the spread of COVID-19. Journal of Travel Medicine. 2020;27(3):1-2. doi: 10.1093/jtm/taaa038

[2] Dehning, J., Zierenberg, J., Spitzner, F. P., Wibral, M., Neto, J. P., Wilczek, M., \& Priesemann, V. Inferring change points in the spread of COVID-19 reveals the effectiveness of interventions. Science. 2020;369(6500):1-10. doi: 10.1126/science.abb9789

[3] Kuchler T, Russel D, Stroebel J. The geographic spread of Covid-19 correlates with structure. NBER working paper series, no 26990). 2020. Available at: http://www.nber.org/papers/w26990

[4] Liew, M. F., Siow, W. T., Yau, Y. W., \& See, K. C. Safe patient transport for COVID-19. Critical Care. 2020;24(1):1-3. doi: 10.1186/s13054-020-2828-4

[5] Katherine L, Jeffrey E. Transportation access to health care during the Covid-19 pandemic: Trends and implications for significant patient populations and health care needs. 2020.

[6] Notoatmodjo S. Metodologi penelitian kesehatan. Jakarta: Rineka Cipta; 2015.

[7] Sugiyono S. Statistika untuk penelitian. Bandung: CV Alfabeta; 2014.

[8] Zhang, M., Zhou, M., Tang, F., Wang, Y., Nie, H., Zhang, L., \& You, G. Knowledge, attitude, and practice regarding COVID-19 among healthcare workers in Henan, China. Journal of Hospital Infection. 2020;105(2):183-187. doi: 10.1016/j.jhin.2020.04.012

[9] Honarvar, B., Lankarani, K., \& Kharmandar, A. Knowledge, attitudes, risk perceptions, and practices of adults toward COVID-19: A population and field-based study from Iran. International Journal of Public Health. 2020;65(6):731-739. doi: 10.1007/s00038020-01406-2 
[10] Girma, S., Alenko, A., \& Agenagnew, L. Knowledge and precautionary behavioral practice toward COVID-19 among health professionals working in public university hospitals in Ethiopia: A web-based survey. 2020.

[11] Zhang, M., Wang, L., Yu, S., Sun, G., Lei, H., \& Wu, W. Status of occupational protection in the Covid-19 fangcang shelter hospital in Wuhan, China. Emerging Microbes \& Infections. 2020:1-26. doi: 10.1080/22221751.2020.1803145

[12] Zhou, Q., Lai, X., Wan, C., Zhang, X., \& Tan, L. Prevalence and impact of burnout, secondary traumatic stress and compassion satisfaction on hand hygiene of healthcare workers in medical aid team during COVID-19 pandemic. 2020:1-16. doi: 10.21203/rs.3.rs-28820/v1

[13] Fu, R., Wu, L., Zhang, C., Chu, Q., Hu, J., Lin, G., ... \& Zhong, W. Z. Real-world scenario of patients with lung cancer amid the Covid-19 pandemic in China. International Association for the Study of Lung Cancer; JTO clinical and research reports. 2020. doi:10.1016/j.jtocrr.2020.100053

[14] Zheng, P., Zhou, R., Yin, L., Yin, X., Mao, Y., Wang, H., ... \& Zhu, T. Emergency response measures for anesthesia nursing during the Covid-19 pandemic: West China hospital experiences. Frontiers in Medicine. 2020;7( July). doi: 10.3389/fmed.2020.00460

[15] Siow, W. T., Liew, M. F., Shrestha, B. R., Muchtar, F., \& See, K. C. Managing COVID-19 in resource-limited settings: Critical care considerations. Critical Care. 2020:1-5.

[16] Rudilosso, S., Laredo, C., Vera, V., Vargas, M., Renú, A., Llull, L., ... \& Chamorro, Á.. Acute stroke care is at risk in the era of COVID-19: Experience at a comprehensive stroke center in barcelona. Stroke. 2020;July:1991-1995. doi: 10.1161/STROKEAHA.120.030329

[17] Li, S., Feng, B., Liao, W., \& Pan, W.. Internet use, risk awareness, and demographic characteristics associated with engagement in preventive behaviors and testing: Cross-sectional survey on COVID-19 in the United States Corresponding Author. Journal of medical Internet research. 2020;22:1-12. doi: 10.2196/19782

[18] Upadhyaya, D. P., Paudel, R., Acharya, D., Khoshnood, K., Lee, K., Park, J. H., ... \& Adhikari, M.. Frontline healthcare workers' knowledge and perception of COVID19 and willingness to work during the pandemic in Nepal: A nationwide crosssectional web-based study. Journal of medical Internet research. Multidisciplinary Digital Publishing Institute. 2020.

[19] Millar RC, Millar RC. Nursing a patient with Covid-19 infection. Journal of EvidenceBased Nursing. 2020:4-8.

[20] Dagne H. Prevention practice and associated factors of coronavirus disease 2019 (COVID-19) outbreak among educated Ethiopians: An online based cross-sectional 
survey. 2020:1-22.

[21] Olaimat, A. N., Aolymat, I., Elsahoryi, N., Shahbaz, H. M., \& Holley, R. A.. Attitudes, anxiety, and behavioral practices regarding Covid-19 among university students in Jordan: A cross-sectional study. The American Journal of Tropical Medicine and Hygiene. 2020:1-7. doi: 10.4269/ajtmh.20-0418

[22] Marques, L. C., Lucca, D. C., Alves, E. O., Fernandes, G. C. M., \& Nascimento, K. C. D. COVID-19: Nursing care for safety in the mobile pre-hospital service. Texto e Contexto Enfermagem. 2020;29:1-12. doi: 10.1590/1980-265x-tce-2020-0119

[23] Adler J. Pre-hospital care \& interfacility transport of 385 COVID-19 emergency patients: An air ambulance. 2020:1-18.

[24] Khosravani, Phavalan N. Hyperacute stroke management during the coronavirus disease 2019 (Covid-19) pandemic. 2020:1891-1895. doi: 10.1161/STROKEAHA.120.029838 